\title{
EFFICIENCY ASSESSMENT OF SLOVAKIAN UNIVERSITIES
}

\author{
MÁRIA GRAUSOVÁ, MIROSLAV HUŽVÁR AND ZUZANA RIGOVÁ \\ Matej Bel University, Banská Bystrica, Faculty of Economics, \\ Department of Quantitative Methods and Information Systems, \\ Tajovského 10,975 90 Banská Bystrica, Slovakia \\ email:maria.grausova@umb.sk, miroslav.huzvar@umb.sk, zuzana.rigova@umb.sk
}

\begin{abstract}
The paper studies the performance of public higher education institutions in Slovakia. Data envelopment analysis is applied to assess the efficiency of selected universities in their two core mission areas: providing education and doing research and development. We focus on how the size and the structure of the academic staff and the capital resources influence the educational and research outputs. Data from public sources for years $2014-2015$ is used in the analysis. Efficiency scores and projections calculated by designed DEA models serve to benchmark assessed universities and provide recommendations for improvement of their performance.
\end{abstract}

Key words: data envelopment analysis, efficiency, public higher education institutions

JEL Codes: $C 44$, I23

DOI: 10.15611/amse.2017.20.15

\section{Introduction}

The objective of this empirical study is to evaluate the performance efficiency of public higher education institutions (HEIs) in Slovakia. We aim to assess how efficient Slovakian public HEIs are in using their labour and capital resources as the key inputs to produce expected outputs in the main areas of their mission, i.e. in education and research, including the research cooperation with a non-academic community. The motivation for the research naturally arises from two reasons. Efficiency in performance brings a comparative advantage to individual HEIs, and efficient and effective use of public resources allocated to public HEIs is expected by all stakeholders. Thus, the results of the analysis may be interesting for university managements as well as for the authorities involved in financing public HEIs.

In Slovakia, general principles of financing public HEIs from the state budget are specified by the Higher Education Act introduced in 2002. The financial support is provided to public HEIs on the base of contracts in the form of subsidies for education and for research and development (R\&D). The allocation criteria are annually updated by the Ministry of Education, Science, Research and Sport of the Slovak Republic. The annual evaluation of the performance of public HEIs for budgetary purposes gives an opportunity for a regular comparison of the HEIs based on numerous indicators. We also apply some of relevant indicators used in the calculation of subsidies and their settings. Other data for the analysis is taken from annual economic and statistical reports published by the ministry and individual HEIs.

Data envelopment analysis (DEA) is applied for efficiency assessment in our study. The paper is organized as follows. In Section 2, we bring a brief overview of previous efficiency studies on universities in other countries based on DEA. In Section 3, we introduce the observed public HEIs, input and output indicators for their efficiency evaluation, and applied 
DEA methodology. Sections 4 and 5 are devoted to present and discuss the empirical results. Then we summarize our findings and outline topics for further research.

\section{State of the Art}

DEA has been applied for evaluating the relative efficiency of universities in several countries. Abbott and Doucouliagosa (2003) studied the efficiency of 36 Australian universities. Johnes (2005) used DEA to the measurement of efficiency in tertiary education in England, comparing 100 HEIs divided into 3 groups. Andersson et al. (2017) studied the technical efficiency and productivity of universities in Sweden. They applied DEA and Malmquist index for evaluating the efficiency of 30 HEIs in years 2005 - 2008. Sagarra, MarMolinero and Agasisti (2017) explored the efficiency of 55 Mexican universities, integrating DEA and multidimensional scaling.

Most of the studies designed a set of DEA models with various combinations of inputs and outputs, input or output orientation and with variable returns to scale. As inputs the studies usually considered teaching, research and other staff, and some approximation for capital, e.g. the value of non-current assets, expenditures on energy and other services, depreciation and interest payable. The most frequently used outputs include the number of students, graduates, scientific publications and research income. Some studies used the number of enrolled students as an input while the number of graduates being an output. Research grants are considered as inputs or outputs. As explanatory variables, Andersson et al. used the share of distance students, university beginners, and the number of education fields.

\section{Data and Methodology}

\subsection{Slovakian public HEIs}

Table 1: List of compared public HEIs

\begin{tabular}{lc}
\hline Public HEI & Shortened name \\
\hline Comenius University in Bratislava & UK \\
Slovak University of Technology in Bratislava & STU \\
Technical University of Košice & TUKE \\
University of Žilina & ŽU \\
Pavol Jozef Šafárik University in Košice & UPJS \\
University of Economics in Bratislava & EU \\
Matej Bel University in Banská Bystrica & UMB \\
Constantine the Philosopher University in Nitra & UKF \\
University of Prešov in Prešov & PU \\
Slovak University of Agriculture in Nitra & SPU \\
The Catholic University in Ružomberok & KU \\
Trnava University in Trnava & TVU \\
University of Ss. Cyril and Methodius in Trnava & UCM \\
Technical University in Zvolen & TUZVO \\
Alexander Dubček University of Trenčín & TUAD \\
J. Selye University in Komárno & UJS \\
\hline
\end{tabular}

Source: The authors.

We do the assessment for 16 out of 20 Slovakian public HEIs, all of them having the official status of universities. Among the four public HEIs excluded from the analysis there are three academies of arts that much differ from the other universities in their creative 
activities along with University of Veterinary Medicine and Pharmacy in Košice which has a unique and narrow specialization in education and research. The list of public HEIs in consideration is given in Table 1 .

UK and UPJŠ represent universities of traditional type, covering natural sciences, social sciences, humanities, and applied sciences including medicine, with a significant share of each branch of science on their educational and R\&D activities. On the contrary, only one or two branches of science dominate in all other public HEIs. STU, TUKE, and ŽU are mostly technical universities. SPU and TUZVO specialize in agriculture and forestry, respectively. The other universities are mostly specialized in social sciences and humanities.

We assess the efficiency of public HEIs from two viewpoints corresponding to the main areas of their mission. We focus on education as well as on high-level publishing outputs from their R\&D activities. Although the education and R\&D are expected to be joint processes at universities, each of these viewpoints is targeted by a separate DEA models in our paper. The reason for a separate efficiency assessment is to avoid technical restrictions on the total number of inputs and outputs, resulting from the relatively small number of assessed HEIs and the properties of applied DEA methodology as we discuss in Section 5.

\subsection{Indicators for Efficiency Assessment}

In general, the selection of indicators for efficiency assessment depends on the assessment objectives, examined production technology, and available data sources.

The objective of efficiency assessment in education is to reveal how efficiently the main human and capital resources involved in education at universities are used for teaching students and preparing them for the job market.

In order to assess the efficiency of Slovakian public HEIs in education, we take into account the teaching staff, the tangible assets, the number of students and the employment of graduates.

The number of teachers, calculated with respect to part time contracts, is considered as an input since teachers are crucial workforce for providing education. Tangible assets represent another important input. Since it is hard to clearly determine the value of assets used directly for educational purposes, we estimate it by the value of all buildings owned by universities (taken from their annual balanced sheets' ${ }^{1}$ ), assuming that they are primarily used for education and supporting services at all universities.

The total number of students as an output is counted for all bachelor, master and doctoral study programs and adjusted by coefficients that represent the relative weights of the form and economic demands of their study programs. The weight of a full time student and a part time student is 1 and 0.3 , respectively. The economic demands of study programs are expressed with special coefficients assigned to corresponding study fields which are applied by the ministry for the calculation of subsidies allocated from the state budget to public HEIs ${ }^{2}$. The coefficients express the relative prices given to university from public sources per one student or graduate of the study program if the student is not obliged to pay a fee for study. Thus, adjusted number of students and graduates estimates the total value of educational activities of the university.

Figure 1 shows the differences among Slovakian public HEIs in average study program coefficients, calculated as the sum of adjusted number of students for all their study programs divided by the total (non-adjusted) number of students. The highest coefficients are observed

\footnotetext{
${ }^{1}$ Data from Register of Financial Statements available at http://www.registeruz.sk/ (accessed March 20, 2017).

2 Data from the Ministry of Education, Science, Research and Sport of the Slovak Republic available at http://www.minedu.sk /677-sk/financovanie/ (accessed March 20, 2017).
} 
for universities of traditional type while the lowest average coefficient is assigned to EU which specializes on business study programs.

To capture the quality of graduates, we take into account their employment on the labour market. In order to distinguish the most successful universities from the rest, the number of unemployed graduates, also adjusted by the study field coefficients, is considered as an undesired output in our educational models.

The objective of efficiency assessment in R\&D is to show how efficient the observed public HEIs are in producing publications of the most influential categories, compared to their human and financial resources available for R\&D.

In order to assess the efficiency of universities in publishing activities we consider the academic staff and the received financial grants as inputs, and high-level scientific and educational publications as a unique output.

Figure 1: Average coefficients of study programs

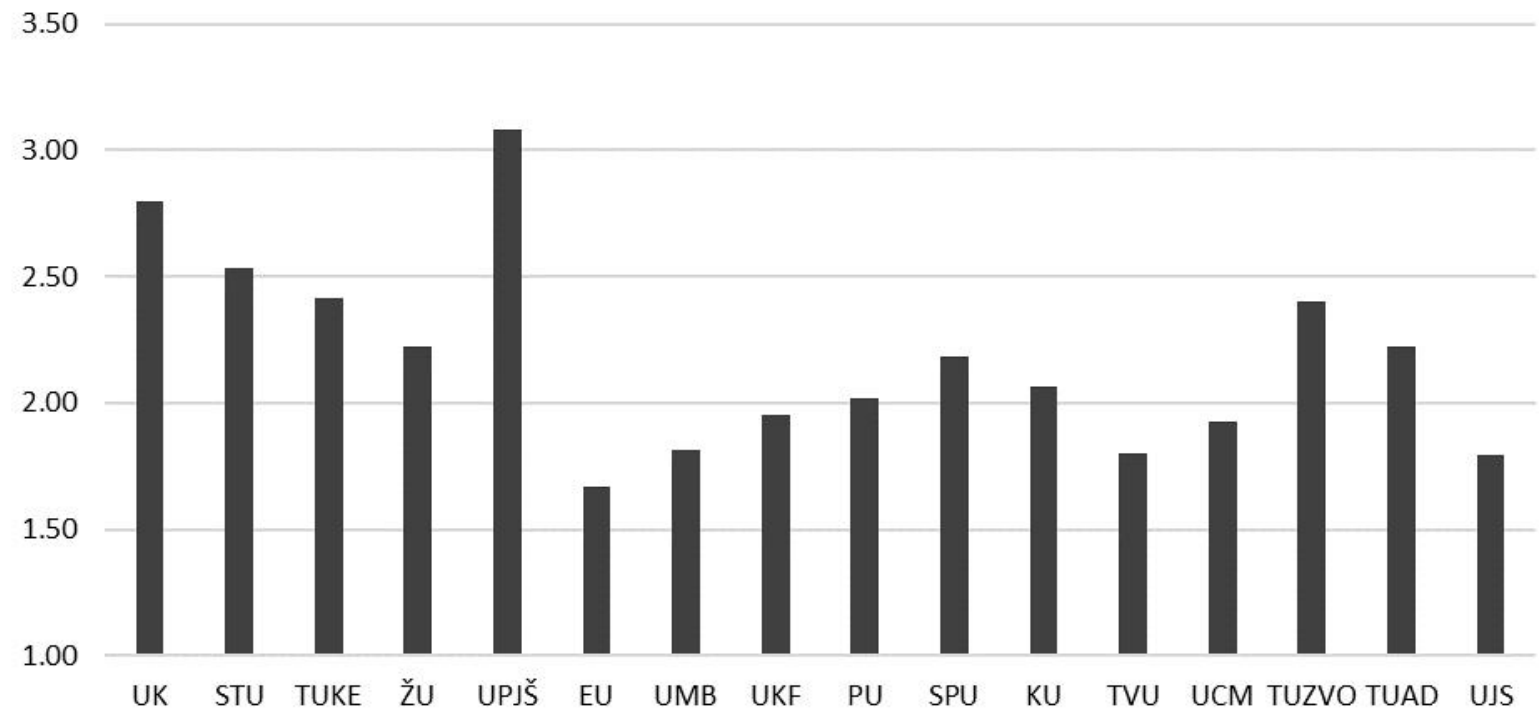

Source: The authors based on data published by the Ministry of Education, Science, Research and Sport of the Slovak Republic ${ }^{2}$.

The academic staff is expressed as the number of teachers (without lectors) and researchers, adjusted with respect to their part time contracts. These two groups of university employees represent the key labour resources involved in preparing the publications.

The grants include all money received from home and foreign research agencies as well as from other organizational and private sources (with the exception of EU operational programs that were primarily used for building and innovation of the university infrastructure). In contrast with subsidies from the state budget, the grants represent the main sources of financial support for research and educational activities that are usually not used for salaries of academic staff in Slovakia. Thus, the total amount of received grants estimates the financial inputs for academic publishing.

Scientific publications of wide potential impact such as monographs, chapters in scholarly books, articles in scholarly refereed journals, and registered patents are considered the most significant products of R\&D. The most important publications for educational purposes include textbooks, professional books, expert translations of publications, bibliographies, catalogues, encyclopaedias, dictionaries, anthologies, atlases, etc. In our DEA models on publication, we use the total number of most influential scientific and educational publications as a unique output. 
The efficiency analysis is based on data published by the ministry and used for calculation of subsidies allocated to individual public HEIs on the base of their educational and scientific performance $^{2}$ and on Annual Reports on Higher Education ${ }^{3}$.

\subsection{Data}

In terms of outputs, we refer to the calendar years 2014 and 2015, taking into account the time correspondence between inputs and outputs and the periods for which data on inputs and outputs is available.

In the educational DEA model, the teaching staff is taken as the average number of teachers in the fourth quarter of the year $2014^{2}$. This teaching staff is supposed to provide education in the academic year 2014 - 2015 that is the only academic year completely included in the assessed period. For the same reason, the number of students is counted for the academic year $2014-2015^{2}$ as well. The number of unemployed graduates is derived from the total number of graduates from full time study programs in both years 2014 and 2015, registered by the Central Office of Labour, Social Affairs and Family on 31 December 20152. Since the total value of university buildings does not rapidly change in time, we consider it in the middle of the period of assessment, i.e. at the end of the year 2014'.

In the publication DEA model, we take into account the average academic staff ${ }^{3}$ and the total amount of grants ${ }^{2}$, both observed over a period of three years from 2012 to 2014 . We assume this is the crucial period for preparing the publications published in calendar years 2014 and $2015^{2}$.

The size of assessed universities can be characterized by their academic staff. Figure 2 shows significant differences among compared HEIs. The two biggest ones (UK and STU) as well as the smallest one (UJS) much differ from the others. While the academic staff of UK includes more than 2,000 teachers and researchers, six universities have the academic staff of less than 400 persons.

Figure 2: The academic staff of Slovakian public HEIs

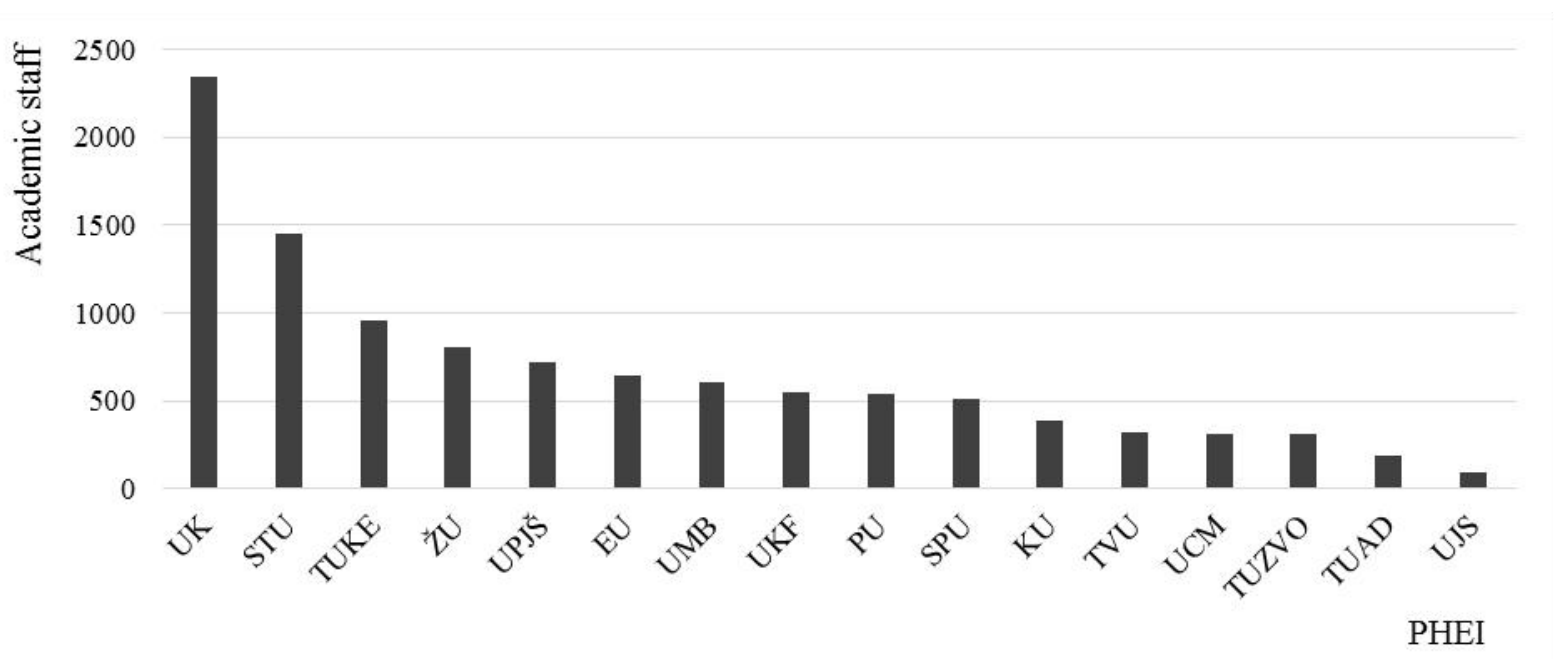

Source: The authors based on data published by the Ministry of Education, Science, Research and Sport of the Slovak Republic ${ }^{3}$.

\footnotetext{
3 Data from the Ministry of Education, Science, Research and Sport of the Slovak Republic available at http://www.minedu.sk /vyrocne-spravy-o-stave-vysokeho-skolstva/ (accessed March 20, 2017).
} 
The differences can also be illustrated by the maximum and minimum values of selected indicators achieved by individual HEIs given in Table 2. UK exhibits the maximum values in all indicators. UJS has the minimum number of academic staff, teachers, students and unemployed graduates, and minimum value of buildings. The smallest amount of grants was received by UCM, and the smallest number of publications was produced by TUAD. Five biggest universities (UK, STU, TUKE, ŽU, UPJŠ) employed $57.2 \%$ of the total academic staff of assessed HEIs, and received $70.6 \%$ of all grants. They also have $56.5 \%$ share on publications, $51.2 \%$ share on adjusted number of students, but only $37.5 \%$ share on unemployed graduates.

Table 2: Extremal values of the indicators

\begin{tabular}{ccc}
\hline Indicator & Maximum & Minimum \\
\hline Academic staff & 2,339 & 95 \\
Teachers & 2,011 & 99 \\
Grants (in $€$ ) & $37,128,336$ & $1,323,204$ \\
Buildings (in $€$ ) & $125,508,333$ & $5,564,726$ \\
Students & 45,322 & 1,751 \\
Unemployed graduates & 1,255 & 169 \\
Publications & 4,108 & 227 \\
\hline
\end{tabular}

Source: The authors based on data published by the Ministry of Education, Science, Research and Sport of the Slovak Republic ${ }^{1,2}$.

Naturally expected dependences between selected inputs and outputs are confirmed with linear regression analysis. However, the number of unemployed graduates is much less correlated with the teaching staff than the number of students (see Table 3). In order to obtain a more detailed insight to the relations between inputs and outputs, we use traditional ratio indicators and compare them with the results of DEA models. This issue will be discussed in Section 4.

Table 3: Correlation matrix

\begin{tabular}{|c|c|c|c|c|c|c|c|}
\hline & Teachers & Buildings & $\begin{array}{l}\text { Unemployed } \\
\text { graduates }\end{array}$ & Students & $\begin{array}{c}\text { Academic } \\
\text { staff }\end{array}$ & Grants & Publications \\
\hline Teachers & 1 & 0.750 & 0.788 & 0.981 & & & \\
\hline Buildings & & 1 & 0.466 & 0.673 & & & \\
\hline $\begin{array}{l}\text { Unemployed } \\
\text { graduates }\end{array}$ & & & 1 & 0.808 & & & \\
\hline Students & & & & 1 & & & \\
\hline Academic staff & & & & & 1 & 0.929 & 0.960 \\
\hline Grants & & & & & & 1 & 0.844 \\
\hline Publications & & & & & & & 1 \\
\hline
\end{tabular}

Source: The authors.

\subsection{DEA Models}

DEA represents a non-parametric approach to ranking decision-making units based on their relative performance efficiencies. DEA is a mathematical programming - based technique for measuring the efficiency of a decision making unit relative to all other units, and thus estimating the best ones within the compared group of units. For each unit, the model provides an efficiency score in the range $(0,1\rangle$, where the value 1 indicates an efficient unit. The 
ranking of units is then determined by the descending order of their scores. For each inefficient unit, DEA identifies the extent and the sources of its inefficiency in terms of input excesses and/or output shortfalls (see Cooper et al., 2007).

We apply for DEA the Slacks-Based Measure (SBM) which reflects all nonzero slacks in inputs and outputs when they are present. We assume variable returns to scale due to rather different sizes of the assessed universities. The non-oriented SBM model (SBM-V) will be used for ranking public HEIs while the oriented SBM models will serve us to identify recommendations for improving their efficiency in inputs or outputs.

The input oriented model (SBM-I-V) will be applied for educational efficiency assessment since the HEIs may intend to optimize their teaching inputs with respect to the number of students since this output can hardly be significantly increased in current demographic situation. Following the approach of Korhonen and Luptáčik (2004), the number of unemployed graduates as an undesirable output is treated as an additional input in our DEA models for efficiency assessment in education.

On the other hand, the output oriented model (SBM-O-V) will be applied for efficiency assessment in publications because we public HEIs may be interested in increasing the publication output produced with existing academic staff and volume of grants.

We use the software DEA Solver ${ }^{4}$ to do the DEA calculations. Applied DEA models are summarized in Table 4.

Table 4: Characteristics of applied DEA models

\begin{tabular}{lll}
\hline & Education model & Publication model \\
\hline Inputs & Teachers & Academic staff \\
& Buildings (in $€$ ) & Grants (in $€$ ) \\
Outputs & Students & Publications \\
& Unemployed graduates & \\
& (undesirable output) & \\
Orientation & Input & Output \\
Returns to scale & Variable & Variable \\
DEA model & SBM & SBM \\
\hline
\end{tabular}

Source: The authors.

\section{Results}

In this section we present the empirical results of our study in the form of tables. Table 5 compares the efficiency scores in education calculated by non-oriented SBM model with selected ratio indicators that are traditionally used to characterize the productivity and quality of education at universities.

By the model, we have 5 efficient HEIs. However, two of them are efficient by default, due to minimum values of inputs (UJS) or maximum value of desirable output (UK). Note that UK reaches the highest share of adjusted students per teacher and also the second lowest unemployment rate of graduates. On the other hand, UJS has the adjusted students per teacher ratio below average and even the highest unemployment rate of graduates. So its efficiency score does not reflect the situation captured by the ratio indicators. The other three efficient HEIs also show different performances. STU dominates in the unemployment rate, having adjusted students per teacher below average. UCM shows similar performance as STU, but reaches worse values in both ratios. PU has a high number of adjusted students per teacher,

\footnotetext{
${ }^{4}$ The software available at http://www.saitech-inc.com/Products/Prod-DSP.asp (accessed March 20, 2017).
} 
but also a relatively high unemployment rate of graduates. Note that the gap between efficient and inefficient HEIs is relatively large. All but one inefficient public HEIs reach the scores below average. The sources of inefficiency will be discussed later in this section.

An average efficiency score for the Publication SBM-V model equals 0.77 and six HEIs occur to be efficient (see Table 6). By default, the efficient universities are UK, due to the largest number of publications, and UJS with UCM, due to the smallest academic staff and the lowest amount of received grants, respectively. Note that UJS dominated in the average number of publications per academic staff while UCM produced the highest number of publications with respect to the amount of received grants. The other efficient universities are TUKE and TVU which produce relatively high numbers of publications per academic staff, and UKF which has the second largest number of publications per the volume of obtained grants. The lowest score is reached by $\check{Z} U$ and EU which also have the lowest number of publications per academic staff. Moreover, ŽU produces the lowest number of publications per $1 €$ of grants.

Table 5: Efficiency scores in education by SBM-V model and related ratios

\begin{tabular}{ccccc}
\hline PHEI & Score & Rank & $\begin{array}{c}\text { Adjusted Students/ } \\
\text { Teachers }\end{array}$ & $\begin{array}{c}\text { Unemployment rate } \\
\text { of graduates }\end{array}$ \\
\hline UK & 1 & 1 & 22.53 & $3.5 \%$ \\
STU & 1 & 1 & 16.99 & $2.6 \%$ \\
TUKE & 0.63 & 12 & 15.26 & $5.1 \%$ \\
ŽU & 0.63 & 11 & 17.76 & $4.2 \%$ \\
UPJS & 0.76 & 8 & 21.76 & $7.3 \%$ \\
EU & 0.52 & 16 & 12.59 & $4.1 \%$ \\
UMB & 0.70 & 9 & 16.65 & $5.3 \%$ \\
UKF & 0.67 & 10 & 19.17 & $6.2 \%$ \\
PU & 1 & 1 & 20.79 & $7.4 \%$ \\
SPU & 0.58 & 13 & 19.38 & $7.2 \%$ \\
KU & 0.57 & 14 & 13.89 & $5.6 \%$ \\
TVU & 0.76 & 7 & 14.94 & $5.6 \%$ \\
UCM & 1 & 1 & 16.41 & $4.7 \%$ \\
TUZVO & 0.56 & 15 & 16.17 & $7.9 \%$ \\
TUAD & 0.89 & 6 & 18.91 & $5.0 \%$ \\
UJS & 1 & 1 & 17.62 & $8.3 \%$ \\
Average & 0.78 & - & 18.37 & $5.6 \%$ \\
\hline
\end{tabular}

Source: The authors.

The ranking of HEIs by non-oriented SBM-V models are shown in Table 5 and Table 6 . Three universities (UK, UJS, UCM) are efficient by both models, but only UCM is not efficient by default in both cases. STU and PU are efficient only in education while TUKE, UKF and TVU only in publications. EU takes worse positions from both viewpoints. We can observe great differences in the two rankings for one half of assessed public HEIs. This fact is also reflected by Spearman's rank-order correlation coefficient (0.435).

In order to improve the education efficiency when preserving the existing numbers of students, universities need to decrease the inputs as well as the undesired output. Thus, we apply input oriented SBM-I-V model to determine the input excesses. As we can see in Table 7, the inefficiency of each HEI is caused by all three factors, but their impacts vary. For majority of universities, the model reveals one or two inputs as main inefficiency sources. 
Table 6: Efficiency scores in publications by SBM-V model and related ratios

\begin{tabular}{ccccc}
\hline PHEI & Score & Rank & $\begin{array}{c}\text { Publications/ } \\
\text { Academic Staff }\end{array}$ & $\begin{array}{c}\text { Publications/ } \\
\text { Grants }(10000 €)\end{array}$ \\
\hline UK & 1 & 1 & 1.76 & 1.11 \\
STU & 0.52 & 14 & 1.26 & 0.53 \\
TUKE & 1 & 1 & 2.10 & 1.16 \\
ŽU & 0.39 & 16 & 1.16 & 0.45 \\
UPJS & 0.85 & 8 & 1.93 & 1.13 \\
EU & 0.46 & 15 & 1.05 & 1.39 \\
UMB & 0.81 & 9 & 1.70 & 1.78 \\
UKF & 1 & 1 & 1.90 & 2.46 \\
PU & 0.94 & 7 & 1.96 & 1.81 \\
SPU & 0.52 & 13 & 1.54 & 0.75 \\
KU & 0.65 & 11 & 1.56 & 2.26 \\
TVU & 1 & 1 & 2.20 & 1.98 \\
UCM & 1 & 1 & 1.92 & 4.59 \\
TUZVO & 0.69 & 10 & 2.02 & 1.19 \\
TUAD & 0.56 & 12 & 1.23 & 1.36 \\
UJS & 1 & 1 & 2.84 & 1.42 \\
Average & 0.77 & - & 1.67 & 1.05 \\
\hline
\end{tabular}

Source: The authors.

Table 7: Efficiency scores in education by SBM-I-V model and proposed input reductions

\begin{tabular}{ccccc}
\hline PHEI & Score & $\begin{array}{c}\text { Teachers } \\
\text { Excess }(\%)\end{array}$ & $\begin{array}{c}\text { Buildings } \\
\text { Excess }(\%)\end{array}$ & $\begin{array}{c}\text { Unemployed Graduates } \\
\text { Excess }(\%)\end{array}$ \\
\hline UK & 1 & 0 & 0 & 0 \\
STU & 1 & 0 & 0 & 0 \\
TUKE & 0.65 & -30.2 & -23.8 & -51.5 \\
ŽU & 0.65 & -18.5 & -62.5 & -24.1 \\
UPJS & 0.76 & -1.1 & -27.0 & -44.3 \\
EU & 0.57 & -40.9 & -63.2 & -25.3 \\
UMB & 0.73 & -22.9 & -26.1 & -32.4 \\
UKF & 0.68 & -11.8 & -38.3 & -46.8 \\
PU & 1 & 0 & 0 & 0 \\
SPU & 0.59 & -9.9 & -56.2 & -57.9 \\
KU & 0.63 & -33.3 & -47.0 & -31.2 \\
TVU & 0.79 & -27.3 & -10.4 & -25.5 \\
UCM & 1 & 0 & 0 & 0 \\
TUZVO & 0.60 & -20.1 & -56.2 & -45.2 \\
TUAD & 0.90 & -2.8 & -24.9 & -2.3 \\
UJS & 1 & 0 & 0 & 0 \\
\hline
\end{tabular}

Source: The authors.

In order to identify the potential for improvement in publication activities, we apply output oriented SBM-O-V model since we aim to maximize the publishing output with respect to existing academic staff and obtained grants. As shown in Table 8, the model reveals the highest output shortfalls for ŽU, TUAD, EU, and STU. Besides that, it also identifies some 
input excesses on grants for STU, ŽU, and SPU, and a slight excess in the academic staff for EU.

\section{Discussion}

The advantages of DEA for efficiency assessment in public sector, compared to alternative techniques, are generally known and widely discussed in literature. The possibility of simultaneous treatment of multiple inputs and outputs to provide a complex efficiency measure and valuable managerial recommendations for efficiency improvement belongs to highly appreciated DEA features. However, the discrimination power of DEA models, i.e. their ability to distinguish the best performances from the rest, decreases with the increasing number of input and output indicators included to the analysis.

Table 8: Efficiency scores in publications by SBM-O-V model and proposed projections

\begin{tabular}{ccccc}
\hline PHEI & Score & $\begin{array}{c}\text { Academic Staff } \\
\text { Excess }(\%)\end{array}$ & $\begin{array}{c}\text { Grants } \\
\text { Excess }(\%)\end{array}$ & $\begin{array}{c}\text { Publications } \\
\text { Shortfall (\%) }\end{array}$ \\
\hline UK & 1 & 0 & 0 & 0 \\
STU & 0.66 & 0 & -30.0 & 50.5 \\
TUKE & 1 & 0 & 0 & 0 \\
ŽU & 0.55 & 0 & -29.2 & 82.0 \\
UPJŠ & 0.91 & 0 & 0 & 9.7 \\
EU & 0.61 & -9.4 & 0 & 63.5 \\
UMB & 0.89 & 0 & 0 & 12.7 \\
UKF & 1 & 0 & 0 & 0 \\
PU & 0.98 & 0 & 0 & 2.1 \\
SPU & 0.71 & 0 & -10.0 & 41.4 \\
KU & 0.79 & 0 & 0 & 25.8 \\
TVU & 1 & 0 & 0 & 0 \\
UCM & 1 & 0 & 0 & 0 \\
TUZVO & 0.90 & 0 & 0 & 11.7 \\
TUAD & 0.56 & 0 & 0 & 0 \\
UJS & 1 & 0 & 0 & 0 \\
\hline
\end{tabular}

Source: The authors.

Hence, the small number of comparable public HEIs in Slovakia critically restricts the application of DEA for their efficiency assessment by a single DEA model. For this reason, we assess the efficiency by separate DEA models, each of them focusing on one of the key mission areas of HEIs. This approach allows us to more carefully identify and express the key inputs for individual areas, e.g. consider the teaching staff as the crucial input for education and the total academic staff contributing to $R \& D$ in the study of publications.

Nevertheless, providing education and doing R\&D represent joint production processes at universities and it is practically impossible to completely separate them in terms of inputs and outputs. In fact, their joint character is still partially present in our DEA models as well. For instance, doctoral students are included to the adjusted number of students as an output of educational DEA model although they are primarily expected to do the research during their study. On the other hand, financial funds received from educational grants and publications intended to support education are involved in the DEA model assessing the efficiency of HEIs in publishing activities. 
The average scores and the number of efficient universities in both models are almost equal, so their discrimination power is comparable. Seven PHEIs are more efficient in the education DEA model (STU, ŽU, EU, PU, SPU, TVU, and TUAD), other six PHEIs are more efficient by the publication DEA model. Three PHEIs (UK, UCM, UJS) are efficient by both models, but only UCM is not efficient by default in both areas (only in publications). PU also shows very good performance in both areas, being efficient by the education model and very close to the efficiency frontier by the publication model. However, most PHEIs achieve substantially different results in the two assessment areas. It indicates that these PHEIs are relatively more efficient in one area than in the other. For example, STU is efficient in education, but reaches one of the lowest efficiency scores in publications. On the contrary, TUKE, UKF and TVU are efficient in publications but their efficiency scores in education are below the average. However, the correspondence between the performance efficiencies observed from different viewpoints and the prevailing specialization of study programs and R\&D activities of individual universities specified in Section 3 is not be evident.

\section{Conclusion}

In the paper we summarized the results of empirical research on the performance efficiency of Slovakian public HEIs. We applied DEA for efficiency assessment and, mostly due to technical restrictions resulting from the DEA technology, we studied the efficiency of HEIs from two viewpoints corresponding to their main mission areas.

When studying the efficiency in education, we contrasted the number of students, adjusted regarding to the form and economic demands of their study programs, with the teaching staff and the tangible assets used for education that were estimated by the value of all buildings owned by universities. We also incorporated to the educational DEA model the employment of graduates as an important external indicator of the education quality.

The efficiency of public HEIs in R\&D was estimated by their ability to produce highly influential publications for both educational and scientific purposes that was contrasted with their significant personnel and financial resources devoted to R\&D, i.e. the whole academic staff and the funds received in the form of grants from domestic and foreign research agencies and cooperating organizations.

The main contribution of the paper consists in the design of DEA models appropriate for efficiency assessment of public HEIs in specific national context. The empirical results provide an information on the reasons of inefficiency of individual public HEIs compared to their competitors and may serve the university managements in searching the measures for improvement their performance efficiency.

The research may be extended in several directions. In order to evaluate the position of Slovakian public HEIs in international context, their comparison with foreign universities in countries with comparable environment is worth studying. Useful results may also arise from efficiency analysis within the groups of faculties by their specialization. All these efficiency studies should be done in a longer period to capture the efficiency change in time. Finally, an identification of explanatory variables that significantly influence the performance efficiency of public HEIs is another challenge for further research.

\section{References}

[1] Abbott, M., Doucouliagos, C. 2003. The efficiency of Australian universities: a data envelopment analysis. Economics of Education Review, vol. 22, issue 1, pp. 89-97. 
[2] Andersson, C., et al. 2017. Technical efficiency and productivity for higher education institutions in Sweden. Scandinavian journal of educational research, vol. 61, issue 2, pp. 205-223.

[3] Cooper W. W., Seiford L. M., Tone K. 2007. Data Envelopment Analysis: A Comprehensive Text with Models, Applications, References and DEA-Solver Software. Springer, Heidelberg.

[4] Johnes, J. 2006. Data envelopment analysis and its application to the measurement of efficiency in higher education. Economics of Education Review, vol. 25, issue 3, pp. 273 288

[5] Korhonen P. J., Luptáčik, M. 2004. Eco-Efficiency Analysis of Power Plants: An Extension of Data Envelopment Analysis. European Journal of Operational Research, vol. 154, issue 2, pp. 437-446.

[6] Sagarra, M., Mar-Molinero, C., Agasisti, T. 2017. Exploring the efficiency of Mexican universities: Integrating Data Envelopment Analysis and Multidimensional Scaling. Omega-international journal of management science, vol. 67, pp. 123-133. 